\title{
Development of Real Estate Market in the Czech Republic
}

\author{
L. Jilemnická, V. Berka, E. Hromada
}

The article deals with analysis of the current situation on the real estate market in the Czech Republic. Software EVAL, which continually collects, examines and evaluates advertised quotations of real estates, was used for mapping and evaluation of the real estate market development. The article provides professional public with detailed view on the time progress of quotations and tenancy of flat units in dependence on the significant parameters of properties and a locality.

Keywords: Real estate market, property market value, statistics.

\section{Introduction}

The faculty of Civil Engineering of the Czech Technical University in Prague is developing special software for systematic monitoring and analysis of the development of advertised quotations for properties. The software has been in operation since September 2007, and in that time it has collected over 650000 offers for sale and tenancy of flats, family houses and real estate lands [1].

Since the launch of the software and the start-up of data collection the research team has been working on improving the analytic tools and specifying inquiries for enlarging the quotation database. Currently the research work focuses on improving the quality of the software in the field of data filtration. Each recorded quotation is assessed in terms of the objectivity and correctness of the presented information. It is compared with older quotations, advertised properties are repeatedly searched, the completeness of the presented information is assessed, etc. About 270 potential faults, deliberately misrepresented information and manipulative practices are totally verified for each quotation. If any small discrepancy is found, the assessed quotation is discarded from the evaluation [2].

\section{Results of research}

In the first quarter of 2008, the prices of energy, foods and services rose very considerably in the Czech Republic. At the same time, a slight rise in the cost of loans (particularly mortgage loans) was recorded. As against the same period in 2007, the interest rates increased by $0.6 \%$ on average. During the first quarter of 2008, the banks lent out a total of 25.8 billion crowns. This is $8.5 \%$ less than in the first quarter of 2007. Nevertheless, the availability of credit products continues to be good, and this has a significant influence on the development of the market values of residential properties.

The slow growth in interest rates slightly increases the tendency to sell older flats. At the same time, quotations per square metre of residential property floorage have moderately risen. During the last 9 months market prices have

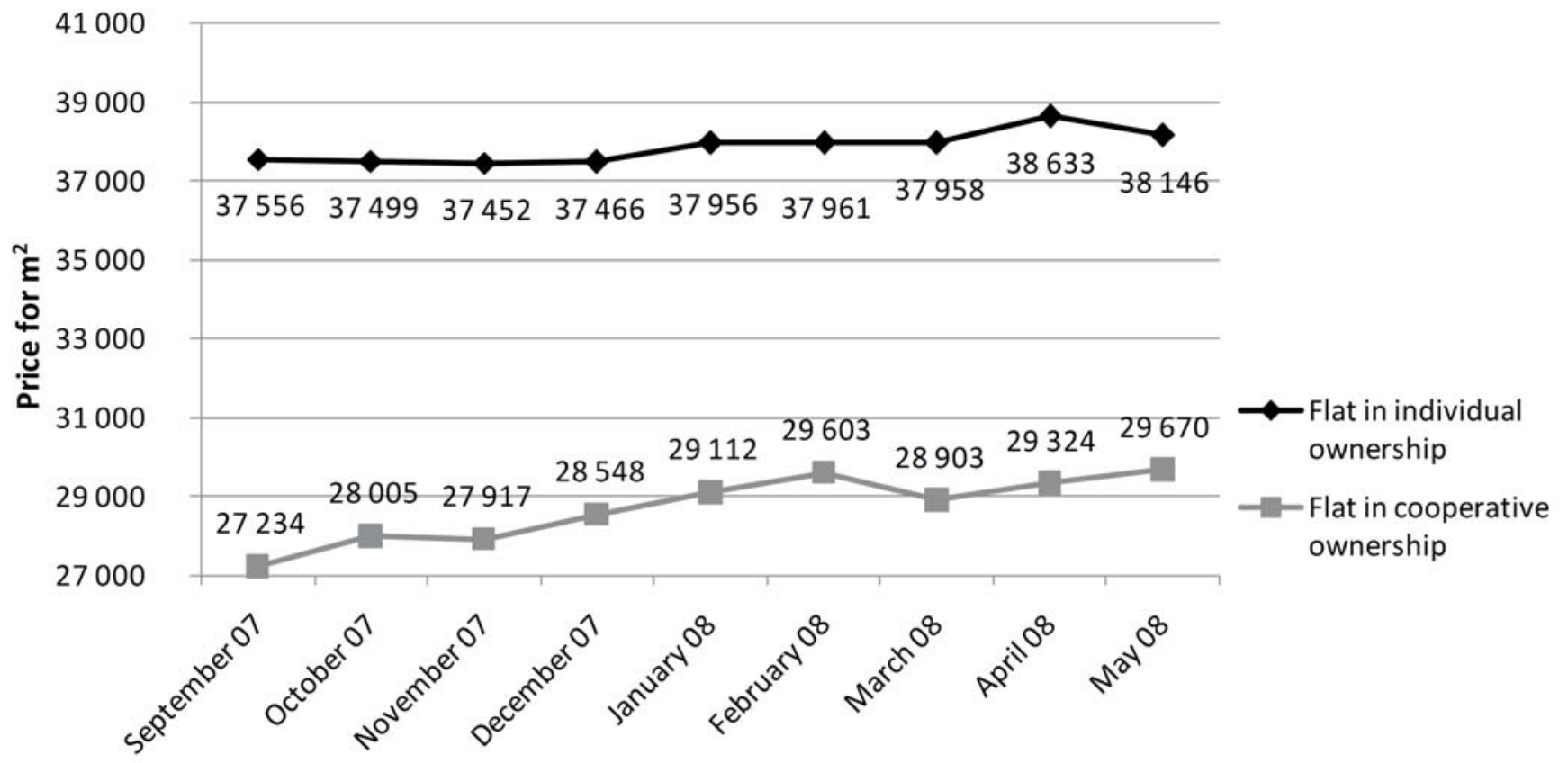

Fig. 1: Average quotation per square metre of older flat units according to type of ownership $(1+\mathrm{kk}$ to $4+1$ category, throughout the Czech Republic) 
Table 1: Categories of flats commonly used in the Czech Republic

\begin{tabular}{|c|c|l|}
\hline $1+\mathrm{kk}$ & $=$ & one room and kitchen corner \\
\hline $2+\mathrm{kk}$ & $=$ & two rooms and kitchen corner \\
\hline $3+\mathrm{kk}$ & $=$ & three rooms and kitchen corner \\
\hline $1+1$ & $=$ & one room and kitchen \\
\hline $2+1$ & $=$ & two rooms and kitchen \\
\hline $3+1$ & $=$ & three rooms and kitchen \\
\hline
\end{tabular}

stagnated or shown a slight rise. There continues to be a quite considerable difference (about $25 \%$ ) between the market price of an older flat directly owned and the market price of an older cooperative flat also keeps on (see Fig. 1). Some examples of the categories of flats and their marking used in this paper are given in Table 1.

It follows from a comparison of the frequency of records in the EVAL software database that the type of flats most offered for sale are flats in the $3+1 / 3+k k$ category (see Fig. 2 ). The increasing number of recorded offers in time testifies to the growing offer of individually owned flats. A similar trend can also be observed in the tenancy of older flats. The types of flats most offered for rent are flats in the $2+1 / 2+\mathrm{kk}$ and $3+1 / 3+$ kk category (see Fig. 3).

Quotations per square metre of flat floorage differ according to the type of flat, its total size, disposition, locality and many other factors. It is clear from Fig. 4 that prices per square metre of flat floorage in the biggest flats show an unstable falling trend over the last 9 months. The trend for other flats is slightly rising. This may be due to a slight increase in

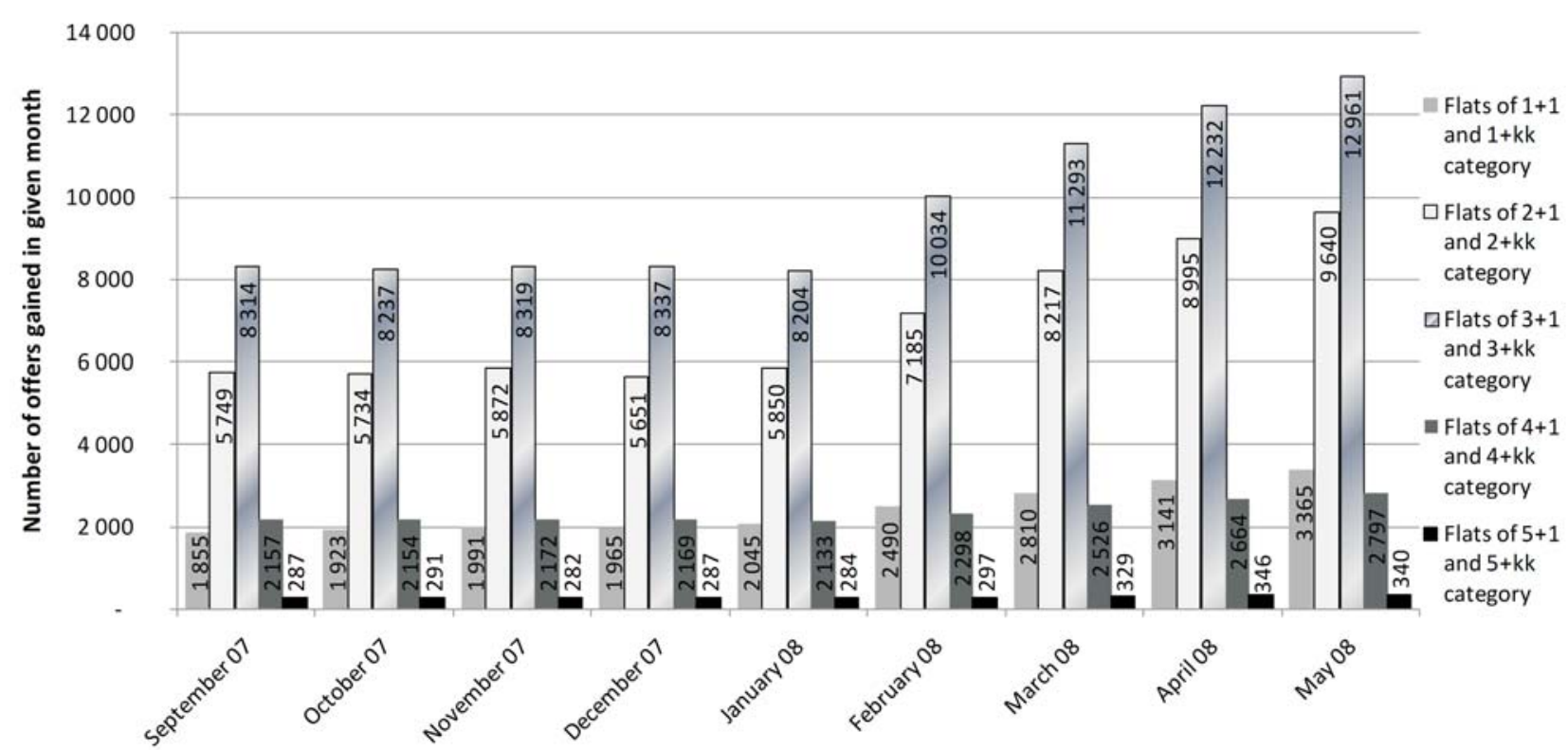

Fig. 2: Number of offers for sale of older flat units recorded by EVAL software in individual months throughout the Czech Republic. This is not a cumulative number of records.

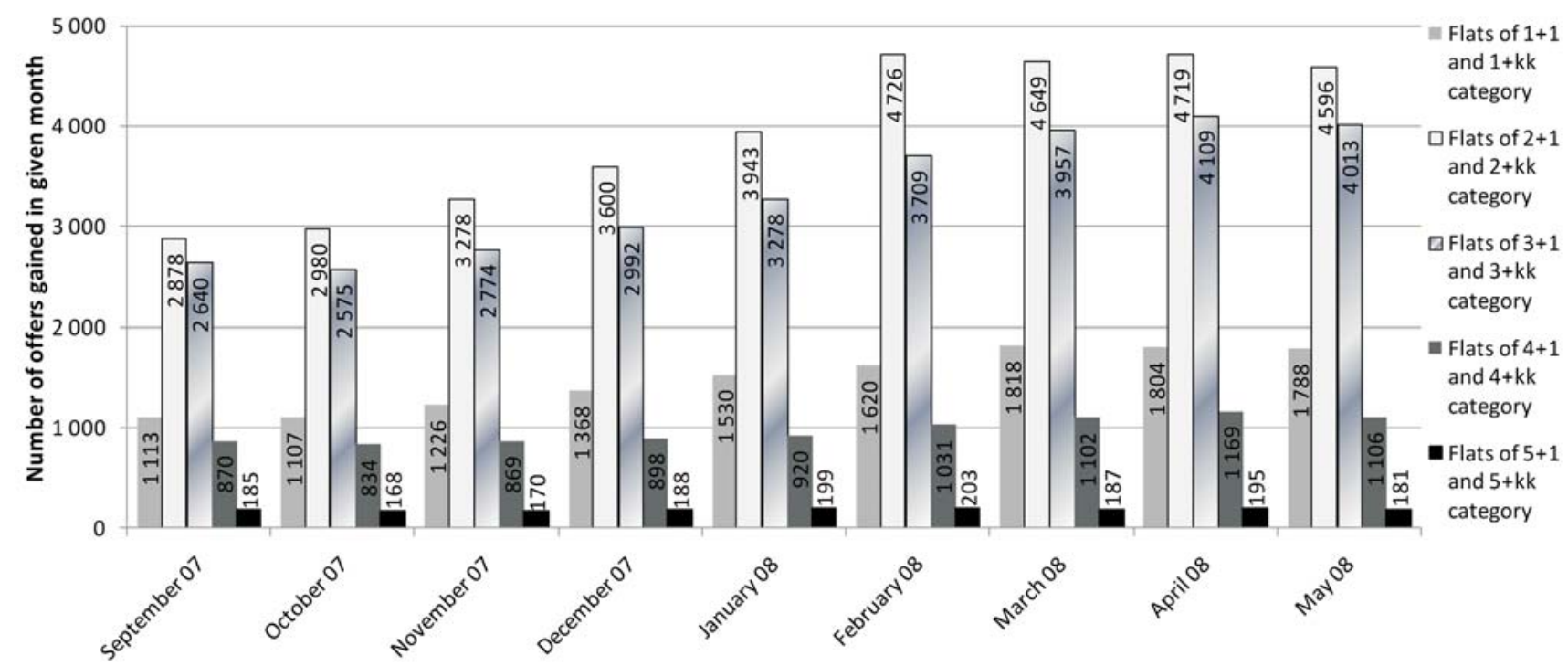

Fig. 3: Number of offers for tenancy of older flat units recorded by EVAL software in individual months throughout the Czech Republic. This is not a cumulative number of records. 


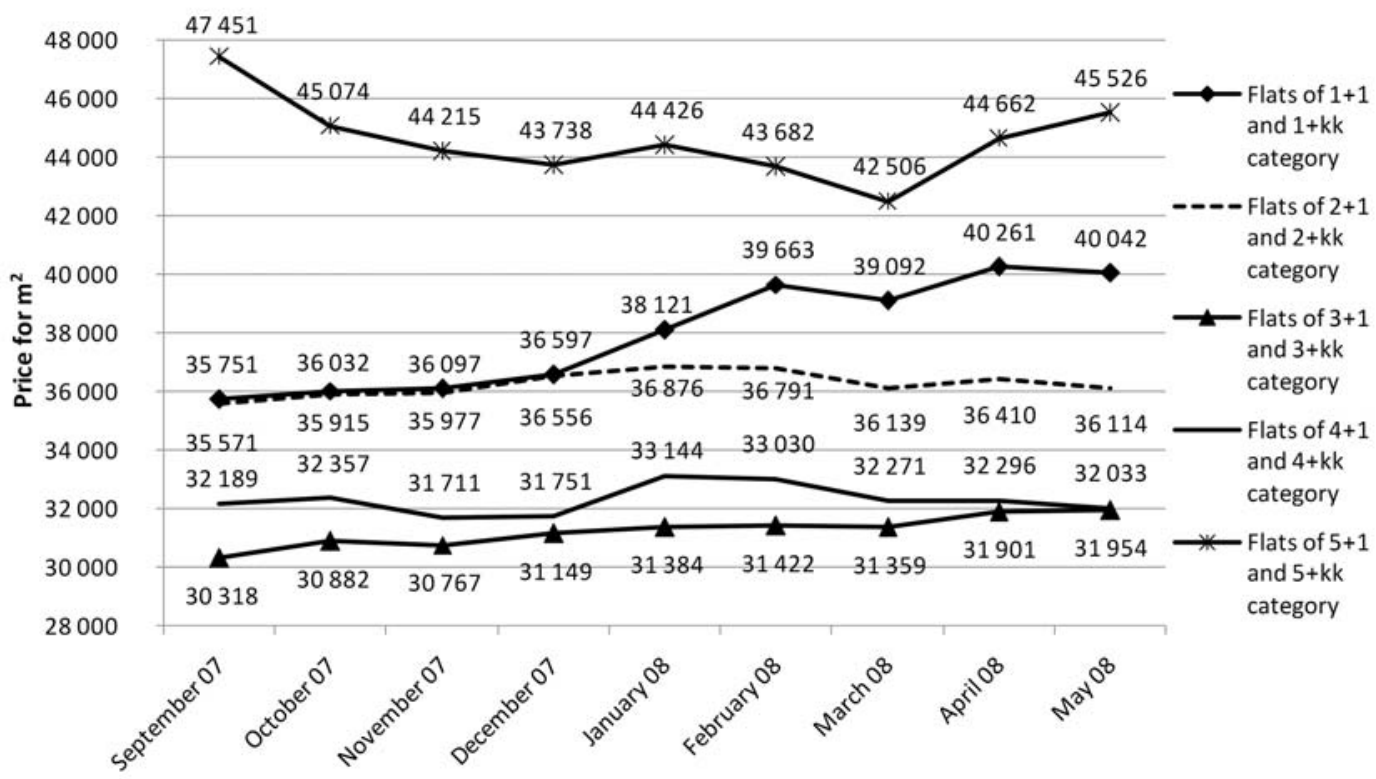

Fig. 4: Average quotations per square metre of older flat units according to category of flat throughout the Czech Republic.

mortgage interest rates and a decrease in mortgages for financing the purchase of the most expensive category of flats. For the lower categories of flats (with a lower purchase price) various forms of financing are still well available. For this reason, there is no substantial limitation at prices at the lower categories of flats. If this hypothesis is confirmed, we can assume a future fall in prices per square metre in the $5+\mathrm{kk}$ and $5+1$ categories. In the future period, a slight drop in prices per square metre for the $4+\mathrm{kk}$ and $4+1$ categories may occur, and then (probably after a period of time) also in the $3+\mathrm{kk}$ and $3+1$.

The most expensive types of flats per square metre of floorage are flats in the $5+\mathrm{kk}$ and $5+1$ categories. Mostly these are luxurious, duplex and spacious roof flats with terraces located in good localities. By contrast, the second most expensive are flats in the lowest $1+\mathrm{kk}, 1+1$ and $2+\mathrm{kk}, 2+1$ category. These are so-called „starter“ flats for young couples, individuals and maybe foreigners, often purchasing their first housing on mortgage to live in on a temporary basis. The next category is $4+\mathrm{kk}, 4+1$ flats, followed finally by the $3+\mathrm{kk}$, $3+1$ category.

This sequence of comparative average prices per square metre of floorage is also influenced by the structural and material characteristics of other flat units. For example, small flats (in the $1+\mathrm{kk}$ to $2+1$ category) are most frequently offered in older brick housing developments, where the price is usually higher than, for instance, flats in the $3+\mathrm{kk}, 3+1$ category, which are most frequently available in prefabricated developments.

Fig. 5 shows the material characteristics of flats on offer, and also types of ownership.

For cheaper flats of lower standard, if the total floorage is larger the market price for per square metre will be lower. From the purely economic point of view, the most cost-effec-

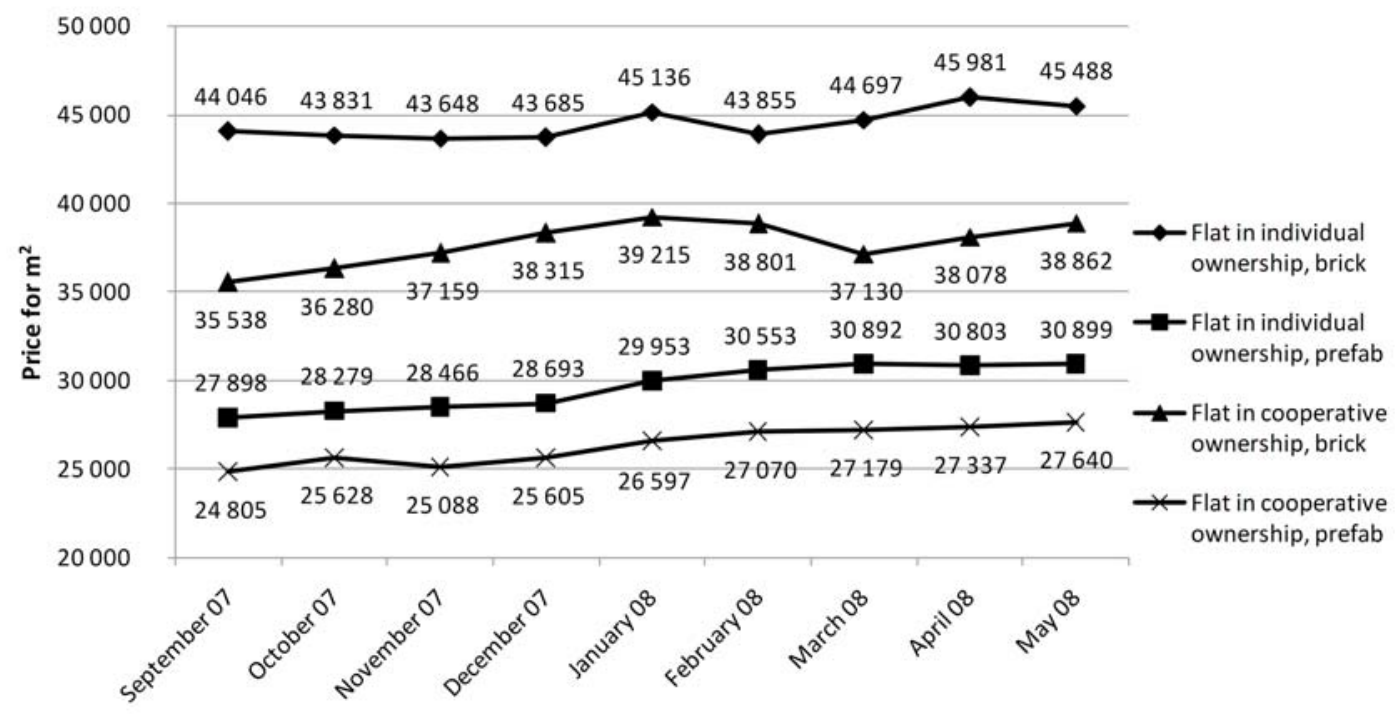

Fig. 5: Average quotations per square metre of older flat units according to material characteristics and type of ownership $(1+k k$ to $4+1$ category, throughout the Czech Republic) 


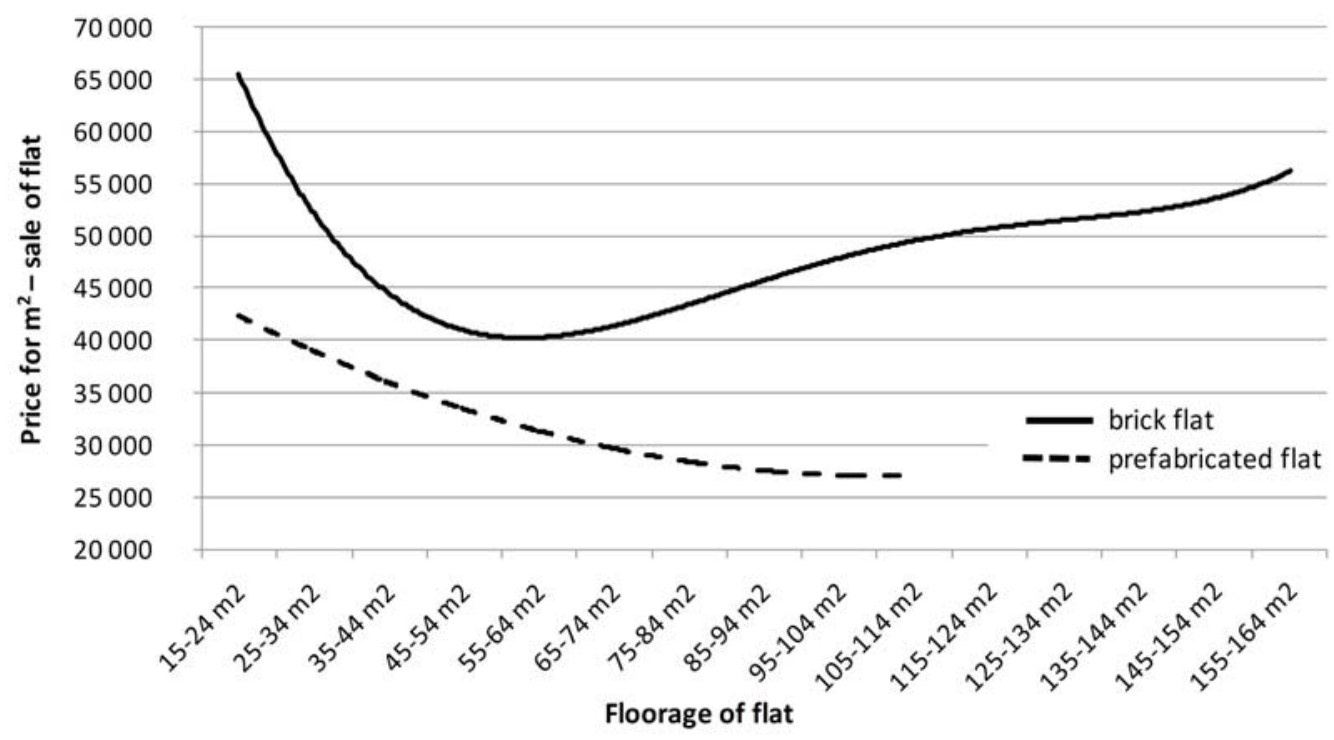

Fig. 6: Dependence of the average quotation per square metre in an older flat unit on flat floorage and material characteristics $(1+\mathrm{kk}$ to $5+1$ category, throughout the Czech Republic)

tive purchase is of a $3+\mathrm{kk} / 3+1$ flat with a floorage of about $65 \mathrm{~m}^{2}$. The price per square metre for bigger flats of a higher standard is proportionally higher. In contrast, the price per square metre for small (starter) flats is disproportionately high for the standard and level of dwelling that is offered (see Fig. 6).

The Czech real estate market reveals considerable regional disparities in the financial affordability of dwellings [3]. Markedly higher prices than in the other regions are observed in the Prague region, where quotations are approximately twice as high as in other regions (see Fig. 7). In terms of average gross monthly earnings, Prague is the region with the lowest affordability of dwellings.

\section{Conclusion}

In recent years we have witnessed a significant rise in market prices for all categories of residential properties. This development has been caused particularly by the availability of mortgages for a relatively broad group of people. However, lasting recent months this trend has stopped particularly in the case of bigger flats (see Graph 7). Quotations per square metre of floorage for these flats are falling slightly. At the same time, we can observe a slight growth in offers for sale of older flats. This may be due to many factors, e.g. seasonal fluctuations or accidental features. However, the sequence of changes of trends indicates that these changes may be due to

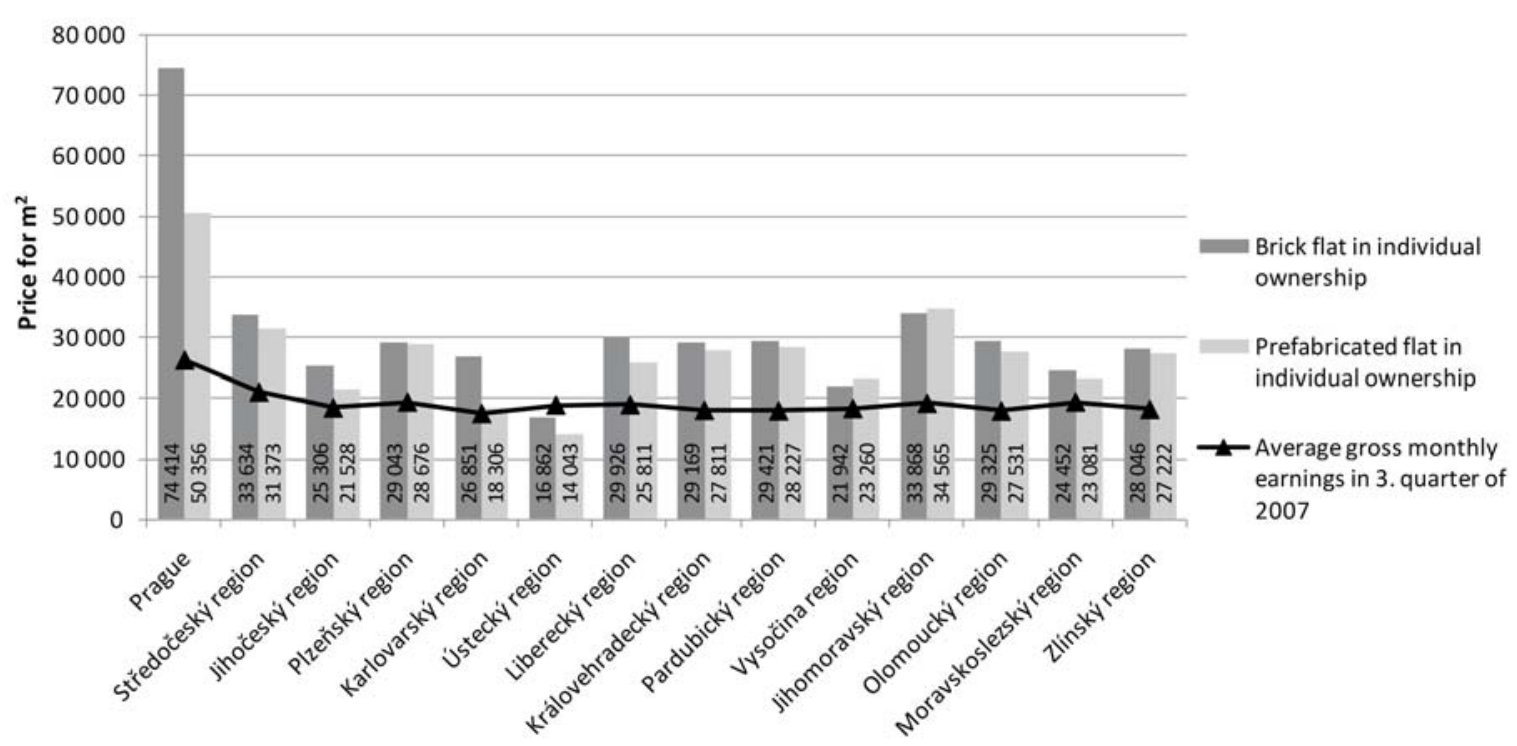

Fig. 7: Average quotations per square metre of older flat units in individual ownership according to regions and material characteristics (1+kk to 4+1 category, May 2008) 
common basic cause - the growth of mortgage rates and a gradual decrease in the revenues from rented properties.

\section{Acknowledgment}

This paper originated as part of a research project at Czech Technical University in Prague, Faculty of Civil Engineering on Management of Sustainable Development of the Life Cycle of Buildings, Building Enterprises and Territories (MSM: 6840770006), financed by the Ministry of Education, Youth and Sports of Czech Republic.

\section{References}

[1] Hromada, E.: „Tržní ceny starších bytů v ČR.“ Stavebnictví, March 2008, No. 3, p. 18-20.

[2] Hromada, E.: Analýza vývoje tržních nájmů starších bytů. Stavebnictví, May 2008, No. 5, p. 70-72.

[3] Ort, P.: Oceňování nemovitostí na tržních principech. Prague: Bankovní institut vysoká škola, 2007.
RNDr. Libuše Jilemnická, CSc.

phone: +420224354657

e-mail: jilemnic@fsv.cvut.cz

Department of Languages

Ing. Vilém Berka

phone: +420224353720

e-mail: vilem.berka@fsv.cvut.cz

Ing. Eduard Hromada, Ph.D.

phone: +420224353720

fax: +420 224355439

e-mail: eduard.hromada@fsv.cvut.cz

Dept. of Construction Management and Economics

Czech Technical University in Prague

Faculty of Civil Engineering

Thákurova 7

16629 Prague 6, Czech Republic 